\title{
Brain death: new questions and fresh perspectives
}

\author{
Farr Curlin ${ }^{1}$
}

Published online: 15 November 2019

(c) Springer Nature B.V. 2019

In 1968, an ad hoc committee at Harvard Medical School convened to examine the definition of brain death released a report entitled "A Definition of Irreversible Coma" [1]. In its report, the committee proposed a new criterion for determining that death has occurred-namely, the total loss of brain function. Over the subsequent decade, this criterion of what came to be called "brain death" was widely adopted in clinical practice. In 1981, the President's Commission for the Study of Ethical Problems in Medicine and Biomedical and Behavioral Research reinforced the concept of brain death, endorsing two alternative physiological standards for declaring death: (1) "irreversible cessation of circulatory and respiratory functions" or (2) the "irreversible cessation of all functions of the entire brain, including the brain stem" [2, p. 73]. The commission's report was then translated to the proposed statute entitled the Uniform Determination of Death Act (UDDA), and public health officials went to work to pass this statute in all states with the hope that the adoption of a uniform standard would routinize and bring consistency to declarations of death in the clinical context.

The goals of the President's Commission and proponents of the UDDA are far from achieved, however. We are now going on half a century of persistent controversies and ongoing attempts to change how we define and assess death. Though most states have adopted the UDDA, several have maintained different standards, producing the strange situation in which an individual who is legally dead in one state may come to be (legally) alive if transferred to another. Apart from the challenge of forging a unified definition of death, there is the corollary challenge of getting clinicians to apply definitions in a consistent manner.

The physiological standards for determining that an individual is brain dead have been persistently contested at clinical, scientific, theological, and philosophical levels. Developments in neuroscience have illuminated potential inaccuracies in standard tests for brain function and have made it possible to assess levels of brain function that were previously inaccessible. Apart from the science, disagreements continue regarding which part(s) of the brain must die, or which functions disappear, before the patient can reasonably be declared brain dead. We are learning more

Farr Curlin

farr.curlin@duke.edu

1 Duke University, Durham, NC, USA 
about brain function in patients suffering a persistent vegetative state, introducing new ambiguity in determining which conditions are unequivocally irreversible and which present hope, however slim, for recovery. These problems are brought vividly to life by cases such as that of Jahi McMath, who was successfully maintained on life support for four and a half years after having been declared brain dead [3], and cases like these raise poignant questions about the validity of standard testing and standard criteria for brain death.

In December 2017, a conference was convened at Georgetown University for the purpose of bringing new philosophical and theological analyses to bear on these persistent debates. This special issue has been developed out of the papers initially presented at that conference. The enclosed contributions address questions such as: What counts as brain death? Does death require total cessation of whole-brain functioning, or just partial? Does death occur with dis-integration of the body? What should our standard course of action be for individuals who do not meet traditional whole-brain death criteria, but who nonetheless have profound brain damage? What social forces are driving these debates, and what are the implications of the ways in which the debates are settled? Should those who hold alternative beliefs regarding life and death be granted exceptions to any brain death standard?

Though not part of the initial conference proceedings, the article by David Oderberg has been included, because it addresses issues relevant to the topic, focusing on the implications that establishing a brain death standard has for organ procurement and donation [4]. Oderberg develops an account of death as separation of the soul from the body, taking his cue from a neo-Aristotelian theory of death. In this account, he describes death as occurring with the disintegration of the body. He outlines rival accounts of disintegration while asking whether a lack of integration must be irreversible for death to be declared. Oderberg aims to establish a framework that respects the dead donor rule while addressing concerns that the rule fails to establish a workable threshold for determining when organs may be harvested from a prospective donor.

Robert Veatch's contribution responds to six controversies that he has found salient in the brain death debate, ranging from questions about which kind of testing should be used to assess brain function to overarching questions about whether there can be any criteria sufficient for definitively establishing that an individual is dead [5]. Taking each controversy in turn, Veatch describes what he takes to be the best arguments on each side of these controversies, concluding that there is little hope for forging consensus. He considers in depth the case of Jahi McMath, a young girl who was declared legally brain dead in California but then transferred to New Jersey where she received care in the form of life support until cardiopulmonary death years later. Veatch uses this case to illustrate the practical, clinical problems that result when different definitions of death are employed. Veatch ultimately argues that the rights of individuals should be respected as they choose which definition of death to accept as compatible with their beliefs regarding life and death.

David Hershenov offers an overview of psychological accounts of personal identity. He then argues, contra proponents of such accounts, that there should not be a different criterion or definition of death for the person than there is for the biological, human life [6]. For defenders of psychologistical accounts of personal identity, 
the body of the human animal may be declared dead when it ceases to function biologically and is no longer capable of instantiating life processes, but a second death for the person that inhabits that body is also possible insofar as the person might cease to exist prior to the body's meeting criteria for death. This notion, Hershenov argues, introduces complicated metaphysical problems for declaring any one individual dead. In response, he contends that defenders of psychological accounts of personal identity need not commit themselves to a separate definition of death for the person, but may, consistent with their logic, endorse biological death as a compatible standard for the death of persons. His argument is aimed, in part, at formulating a uniform definition of death that is consistent among animal species.

In his essay, Jeffrey Bishop articulates the historical twists and turns that resulted in both the public and the medical profession's defining death in biological terms [7]. Along the way, he explores the motivations of key figures who participated in what Bishop calls the social construction of brain death. In particular, he argues that the concept of brain death was motivated by a desire to increase the number of organs available for transplant. In support of that claim, he chronicles the shift in language from coma dépassé (or "beyond coma"), describing an individual as barely alive, to brain dead, describing an individual assumed to be already dead. He then questions the epistemological and metaphysical implications of accepting the brain death criterion, constructed this way, as authoritative. Ultimately, he argues that the social and practical reasons we give for defining death are necessarily tied to underlying aesthetic and moral motivations, and he calls for attention to those underlying motivations as we navigate how to best define death.

Melissa Moschella offers an argument by way of analogy, comparing the dis-integration of the body that results from brain death to the lack of integration that results when a traditional orchestra attempts to operate in the absence of a conductor [8]. Much like an orchestra without a conductor, the body without the brain functions as a series of separate parts lacking connection to and coordination by the centralized master part that would serve to unify them. She argues that while developments in technology have allowed for the body to appear integrated and whole, capable of some functioning and completing some biological processes, this appearance is a façade. Unlike less complex organisms, the human organism requires brain functioning for genuine unification, and when this unifying part irreversibly ceases to function, the human organism may be properly declared dead. In this state, the body no longer possesses the organization required to regulate the biological activities necessary to support it as a single entity, instead disintegrating into a series of parts that function independently of the brain-dead whole.

Finally, Daniel Sulmasy argues that the best way forward is not to allow individuals to use different definitions of death, but instead to develop a more defensible, unified definition [9]. He advances several reasons for preferring a single definition of death, including ethical, linguistic, social, and other practical concerns. He distinguishes and outlines, in turn, the following six states of affairs that may satisfy a definition of death: cardiopulmonary death, whole-brain death, higher-brain death, brainstem death, the social standard of death, and the liberal standard of death. He recurs to whole-brain and cardiopulmonary criteria as our most defensible (and most certain) standards for declaring death, but he argues for continued strengthening and 
unification of the definition and criteria for death in order to meet the high demand for epistemic certainty that should attend a declaration with such high stakes. Toward that end, Sulmasy proposes additional tests that should be incorporated so as to most accurately assess whether an individual meets whole-brain criteria for death.

Taken together, these essays not only affirm that controversies about brain death remain quite alive, but also contribute to public and professional appreciation of the nature of these controversies, the reasons they continue, and what is at stake in how they are resolved.

\section{References}

1. Ad Hoc Committee of the Harvard Medical School. 1968. A definition of irreversible coma: Report of the ad hoc committee of the Harvard Medical School to examine the definition of brain death. Journal of the American Medical Association 205: 337-340.

2. President's Commission for the Study of Ethical Problems in Medicine and Biomedical and Behavioral Research. 1981. Defining death: Medical, legal and ethical issues in the definition of death. Washington, DC: United States Government Printing Office.

3. Schmidt, Samantha. 2018. Jahi McMath, the Calif. Girl in life-support controversy, is now dead. Washington Post, June 29. https://wapo.st/2MyLoV6?tid=ss_tw\&utm_term=.e02e95583f5d.

4. Oderberg, David S. 2019. Death, unity, and the brain. Theoretical Medicine and Bioethics. https:// doi.org/10.1007/s11017-019-09479-8.

5. Veatch, Robert M. 2019. New controversies in defining death: A case for choice. Theoretical Medicine and Bioethics. https://doi.org/10.1007/s11017-019-09505-9.

6. Hershenov, David B. 2019. Why psychological accounts of personal identity can accept a brain death criterion and biological definition of death. Theoretical Medicine and Bioethics. https://doi. org/10.1007/s11017-019-09506-8.

7. Bishop, Jeffrey P. 2019. When is somebody just some body? Ethics as first philosophy and the brain death debate. Theoretical Medicine and Bioethics. https://doi.org/10.1007/s11017-019-09508-6.

8. Moschella, Melissa. 2019. The human organism is not a conductorless orchestra: A defense of brain death as true biological death. Theoretical Medicine and Bioethics. https://doi.org/10.1007/s1101 7-019-09501-z.

9. Sulmasy, Daniel P. 2019. Whole-brain death and integration: Realigning the ontological concept with clinical diagnostic tests. Theoretical Medicine and Bioethics. https://doi.org/10.1007/s1101 7-019-09504-w.

Publisher's Note Springer Nature remains neutral with regard to jurisdictional claims in published maps and institutional affiliations. 